\title{
Concomitant chronic spontaneous urticaria treatment might hinder the diagnosis of occupational latex-induced anaphylaxis: A case report
}

\author{
Ploylarp Lertvipapath, ${ }^{1}$ Aree Jameekornrak Taweechue, ${ }^{2}$ Chamard Wongsa, ${ }^{2}$ Torpong Thongngarm, ${ }^{2}$ \\ Waratchaya Uawattanasakul, ${ }^{3}$ Mongkhon Sompornrattanaphan ${ }^{2}$
}

\begin{abstract}
Background: Cutaneous manifestations of chronic spontaneous urticaria (CSU) are identical to type 1 hypersensitivity reactions. The daily occurrence of rash from occupational allergy could be misinterpreted as CSU exacerbation.

Objective: We aim to report a nurse with concomitant CSU suffering from latex-induced anaphylaxis.

Method: Skin tests, specific IgE using ImmunoCAP, and gloves challenge were performed.

Result: A 27-year-old nurse with CSU suffered from several episodes of severe urticarial flare. H1-antihistamine up-dosing and oral corticosteroid burst were given. Unfortunately, she developed 3 episodes of anaphylaxis during her routine nursing care work on a medical ward, leading to allergist consultation. She had positive latex-specific IgE (6.86 $\mathrm{kUA} / \mathrm{L}$ ) and positive gloves challenge test.

Conclusion: Concomitant CSU treatment might hinder the recognition of latex allergy by masking or delaying skin manifestations. IgE-mediated allergy should be suspected if there was a change in severity or frequency of previously controlled CSU or the presence of systemic symptoms.
\end{abstract}

Key words: Anaphylaxis, drug hypersensitivity, hypersensitivity, latex hypersensitivity, nursing, natural rubber latex, skin tests, urticaria

\footnotetext{
Affiliations:

Adverse Drug Reaction Unit, Division of Academic Affairs, Department of Pharmacy, Siriraj Hospital, Mahidol University, Bangkok, Thailand

${ }^{2}$ Division of Allergy and Clinical Immunology, Department of Medicine, Faculty of Medicine Siriraj Hospital, Mahidol University, Bangkok, Thailand

Out-Patient Pharmacy Division, Department of Pharmacy,

Siriraj Hospital, Mahidol University, Bangkok, Thailand
}

\section{Background}

Latex allergy has been recognized for many decades. IgE-mediated anaphylaxis from latex has been reported in various settings, including during medical procedures or peri-operative settings. ${ }^{1,2}$ Health care workers (HCWs) are the occupational group most affected. The current prevalences of latex allergy and sensitization among HCWs worldwide are $9.7 \%$ and $12.4 \%$, respectively. ${ }^{3}$ Cutaneous manifestations of chronic spontaneous urticaria (CSU) are identical to type 1 hypersensitivity reactions. The daily occurrence of rash from occupational allergy could misinterpret as CSU exacerbation

\section{Corresponding author:}

Aree Jameekornrak Taweechue

Division of Allergy and Clinical Immunology,

Department of Medicine, Faculty of Medicine Siriraj Hospital,

Mahidol University, Bangkok, Thailand

E-mail: siaidatabase@gmail.com

due to occupational exposure. In this article, we report a nurse with concomitant CSU suffering from several episodes of latex-induced anaphylaxis.

\section{Case presentation}

We describe a 27-year-old female nurse who had been working in an internal medicine ward for five years consecutively. Her work related to the general nursing care of patients, including bed baths and intravenous drug administration. In her routine work, she had always used latex-powdered gloves. 
Her comorbidity was intermittent nonspecific atopic eczema of hands and arms, and she had been treated with topical corticosteroids. Patch test, using a commercially available kit (T.R.U.E test), was previously performed from a previous private hospital due to eczema of her hands and arms. The results were negative for the panel, including thiuram mix, mercaptobenzothiazole, and carba mix. She denied a history of previous drug and food allergies. Figure 1A summarizes the timeline of events. She had been having daily recurrent wheals and hives for two months and was diagnosed with CSU. She was prescribed hydroxyzine $25 \mathrm{mg} /$ day at bedtime and chlorpheniramine $16 \mathrm{mg} /$ day, which completely controlled her CSU for two months. Nevertheless, two months later, her CSU had flared up of the arms, neck, and hands with intermittent facial erythema for one week, especially during work hours. She could not recall whether her flares were associated with any agents. Another physician prescribed fexofenadine $120 \mathrm{mg} /$ day for treating uncontrolled urticaria and stop the previous medications. Her rash partially improved in severity and frequency. However, mild pruritus with multi-focal erythema still occurred 1-2 times/week. During this period, the physician increased fexofenadine to $240 \mathrm{mg}$ /day to treat her uncontrolled CSU, leading to partial improvement.

A

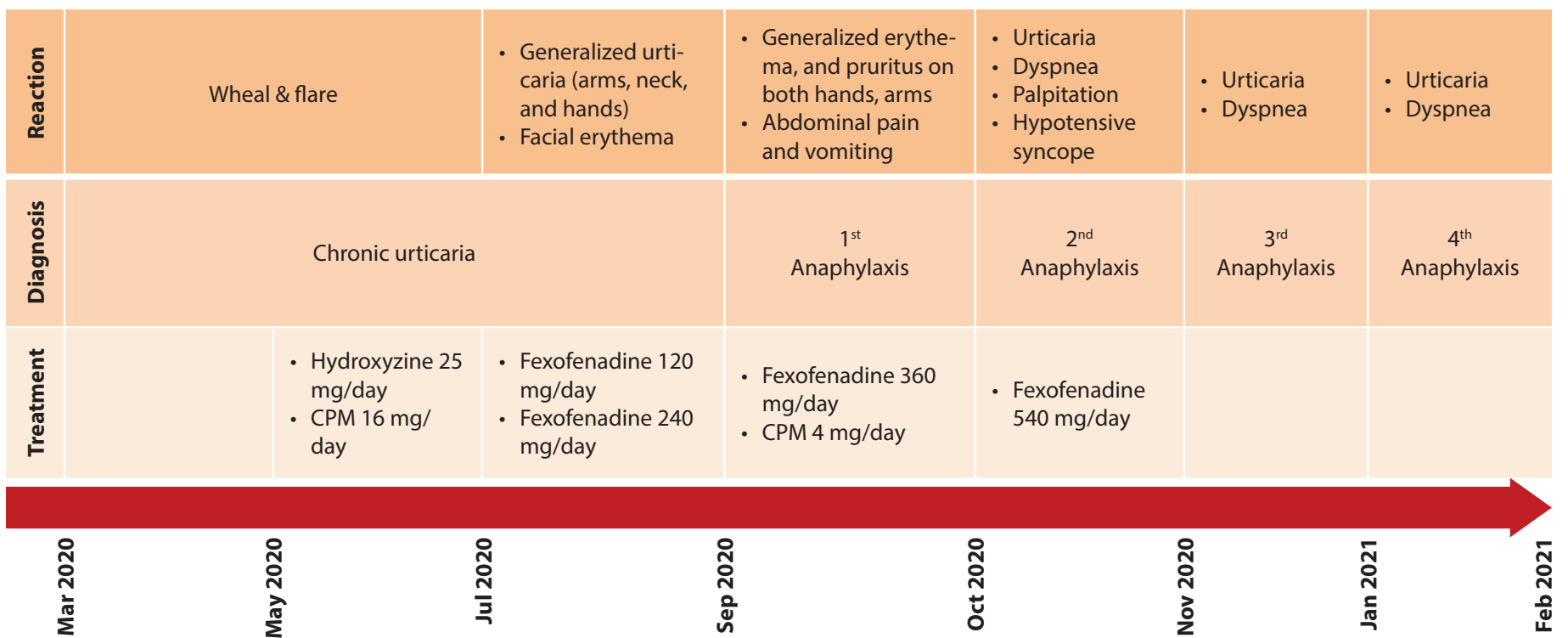
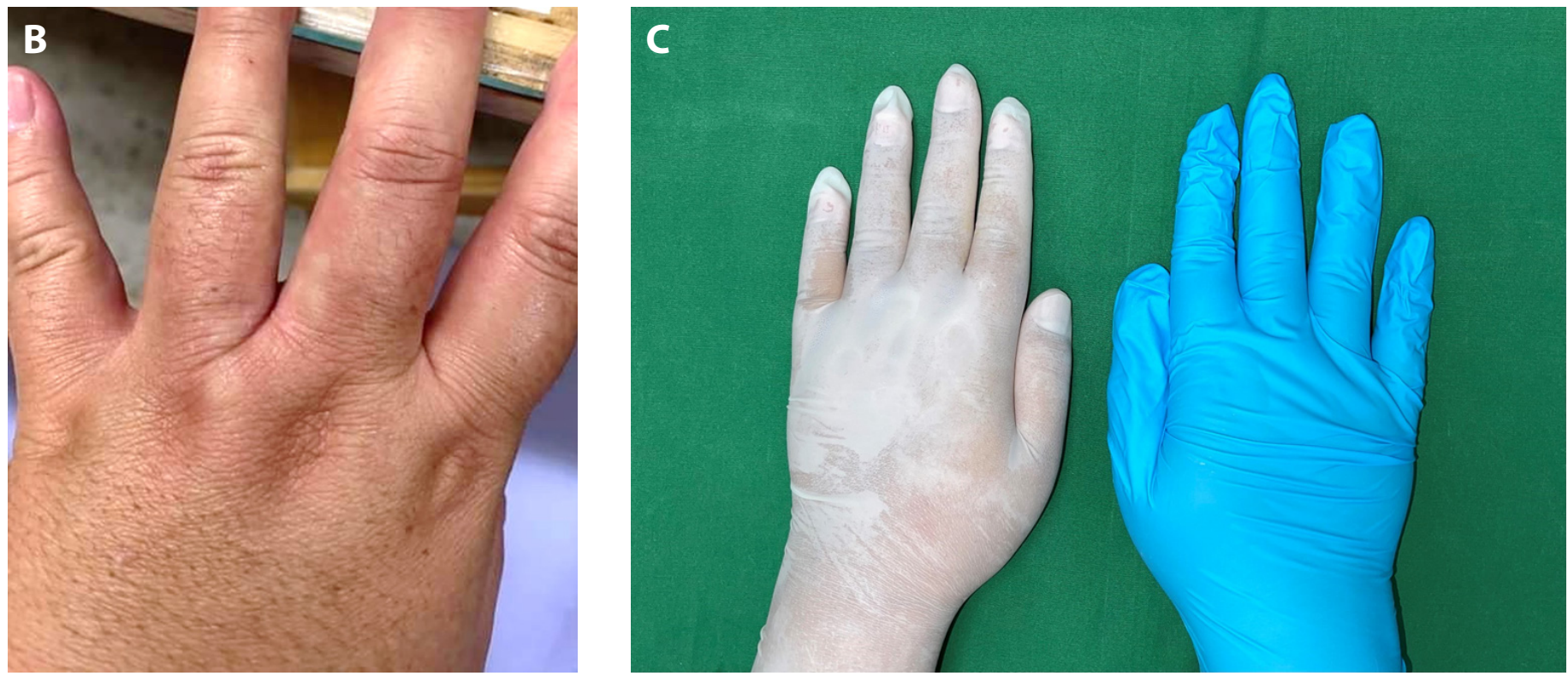

Figure 1 .

1A. Event timeline of the case

1B. The photograph was taken by the patient at the time of reaction, shortly after using latex-powdered gloves.

1C. Gloves challenge test with prick-puncture demonstrated $4 \times 4$ millimeters of a wheal with a flare of the left hand at the site of prick-puncture through the latex-powdered glove.

Abbreviation: CPM, chlorpheniramine; mg, milligram; 


\section{First anaphylaxis}

One month later, she developed generalized erythema and pruritus on both hands and arms along with abdominal pain during routine morning round. She wore latex gloves during morning bed baths and hand washing, and changed gloves 4-5 times, approximately one hour before the onset of symptoms. She received intramuscular epinephrine, intravenous (IV) chlorpheniramine, and dexamethasone, and she was hospitalized. The physician assumed that mushroom curry was the likely causative agent of CSU exacerbation. She was advised to avoid these mushrooms and continued with fexofenadine 360 $\mathrm{mg} /$ day. She additionally self-medicated with over-the-counter chlorpheniramine $4 \mathrm{mg} /$ day in the morning to alleviate her symptoms.

\section{Second anaphylaxis}

She wore latex gloves during mixing a drug in IV vial which took 3-5 minutes, followed by a short distance walk to administer the IV drug to the patient, changing gloves, and washing hands. Ten minutes after washing her hands, she started having hand pruritus and erythema, followed by dizziness. Then she asked her companion to measure her vital signs. Her blood pressure was $80 / 40 \mathrm{mmHg}$. Anaphylaxis treatment was initiated. The event occurred in the afternoon. She was unable to recall her last meal. The same physician prescribed increasing fexofenadine to $540 \mathrm{mg} /$ day. A referral to an allergist was scheduled for the following week, but she did not attend.

\section{Third anaphylaxis}

She developed the third episode of anaphylaxis, which began with pruritus of the hands after wearing latex-powdered gloves (Figure 1B), progressing to generalized urticaria accompanied by dyspnea. She was treated for anaphylaxis, and no biphasic reaction occurred. She came to visit an allergist in the end of November 2020 for evaluation.

\section{The allergist's evaluation}

Physical examination revealed post-inflammatory hyperpigmentation of both cubital fossae and xerosis of both hands without urticarial pigmentosa and active eczema. The latexspecific IgE using ImmunoCAP (Phadia AB, Upsala, Sweden) was $6.86 \mathrm{KUA} / \mathrm{L}$, further confirmed by positive gloves challenge test (Figure 1C). The baseline serum tryptase was $3.04 \mathrm{mcg} / \mathrm{mL}$. The results of other allergologic workup are summarized in Table 1. Spirometry revealed no evidence of obstructive pattern and reversible airflow limitation. The allergist diagnosed her with latex-induced anaphylaxis and recommended that she avoid using latex-containing gloves or devices with the checklist. Self-injectable epinephrine and skin emollient were prescribed. Laboratory investigation was performed. Consideration of task switching was recommended because it would be nearly impossible to avoid latex-containing devices in the medical ward at her local hospital.
Table 1. Allergologic workup results 4 weeks after the third anaphylaxis

\begin{tabular}{|c|c|c|}
\hline Skin prick test ${ }^{\mathrm{a}}$ & Specific IgE $\left.\operatorname{IgUA}^{\dagger} \mathrm{L}\right)$ & Spirometry \\
\hline $\begin{array}{l}\text { Chlorhexidine diglu- } \\
\text { conate } \\
\text { - SPT }(5 \mathrm{mg} / \mathrm{ml}) \text { : } \\
\text { negative } \\
\text { - } \text { IDT }^{\mathrm{b}}(0.002 \mathrm{mg} / \mathrm{ml}) \text { : } \\
\text { negative } \\
\text { Positive control: } \\
5 \times 4 \mathrm{~mm} \\
\text { Negative control: } \\
\text { negative }\end{array}$ & $\begin{array}{l}\text { Latex: } 6.86 \\
\text { Foods } \\
\text { Wheat: } 0.11 \\
\text { Tri a 19: } 0.05 \\
\text { Egg white: } 0.05 \\
\text { Cow's milk: } 0.15 \\
\text { Peanut: } 0.09 \\
\text { Soya bean: } 0.16 \\
\text { Shrimp: } 0.07 \\
\text { Aeroallergens } \\
\text { DP: } 0.09 \\
\text { DF: } 0.05\end{array}$ & $\begin{array}{l}\text { FEV1 (\% Predicted) } \\
\text { - Pre-BD: } 2.12 \mathrm{~L} \\
\text { ( } 88.1 \%) \\
\text { - Post-BD: } 2.40 \mathrm{~L} \\
(89.6 \%) \\
\text { FVC (\% Predicted) } \\
\text { - Pre-BD: } 2.38 \mathrm{~L} \\
\text { ( } 88.2 \%) \\
\text { - Post-BD 2.86 L } \\
\text { (94.5\%) } \\
\text { FEF25-75\%: } \\
\text { 2.17 L/second (82.6\%) }\end{array}$ \\
\hline
\end{tabular}

antradermal test (IDT) result was reported as initial wheal size $(\mathrm{mm})$ and 20 -minute wheal size $(\mathrm{mm})$, respectively. IDT to chlorhexidine $(0.002 \mathrm{mg} / \mathrm{ml})$ was negative.

${ }^{\mathrm{b}}$ A skin prick test (SPT) was performed first on the forearm with the negative and positive control using normal saline and $10 \mathrm{mg} / \mathrm{mL}$ of histamine, respectively. Results were considered positive if a wheal diameter of $\geq 3 \mathrm{~mm}$ was read at 20 minutes. When the SPT was negative, we performed an intradermal test (IDT) on the volar side of the forearm. Results were considered positive if the wheal increased in diameter $\geq 3 \mathrm{~mm}$ compared to the original wheal with concurrent flare. H1-antihistamine was discontinued at least 7 days before performing SPT and IDT.

Abbreviation: BD, Bronchodilator; DP, Dermatophagoides pteronyssinus; DF, Dermatophagoides farinae; FEV1, forced expiratory volume in one second; FVC, forced vital capacity; FEF25-75, forced expiratory flow at 25-75\% of FVC; \% pred, percentage of predicted value; IDT, immediate reading intradermal test; IgE, Immunoglobulin E; kUA/L, kilounits of allergen-specific IgE per liter; mm, millimeter; SPT, skin prick test.

\section{Discussion and Conclusion}

We report a case of a nurse with recurrent IgE-mediated anaphylaxis to latex who had been previously diagnosed as CSU. Latex allergy was confirmed by latex-specific IgE and gloves provocation. HCWs are the occupational group with a high prevalence of latex allergy. ${ }^{3}$ The incidence of latex allergy continues in some countries as a result of high levels of exposure to Hevea allergen, usually associated with duration of exposure. A combination of the pre-existing skin defect, atopic background (atopic eczema), and chronic exposure (nursing procedure) could result in sensitization and allergic reaction, respectively. ${ }^{1,4-6}$ The patient may have been sensitized to natural rubber latex (NRL) protein via direct contact, breathing NRL proteins, especially allergen-containing glove powder. ${ }^{7}$ Cornstarch powder in the gloves has been shown to increase aerosolization of latex protein. Unfortunately, latex powder-containing gloves are still widely used in many hospitals in Thailand. Direct mucosal and parenteral exposure poses the greatest risk of anaphylaxis. ${ }^{8,9}$ The present case had anaphylaxis from impaired keratinized skin from comorbid eczema. In addition, high-dose antihistamines, used in CSU, potentially masked the early cutaneous reaction, leading to continuous exposure to NRL allergen that progressed to hypotensive anaphylaxis. 
Although the number of latex-allergic patients in the general population has been declining, and the use of powdered latex gloves has diminished, the latex-allergic population is still at risk of being overlooked or mismanaged. ${ }^{2}$ The nonspecific symptoms and a lack of knowledge about latex allergy may result in a missed diagnosis. CSU is a common skin condition, ${ }^{10}$ its cutaneous manifestations are identical to type 1 hypersensitivity. ${ }^{11}$ The daily occurrence of urticarial rash could mislead physicians to a diagnosis of CSU. This setting is homologous to that of patients with adult-onset IgE-mediated wheat allergy who had frequent episodes of urticaria preceding anaphylaxis because wheat is contained in various kinds of consumed foods in everyday life. ${ }^{12}$

The limited number of adult allergists and misdiagnosis between urticaria exacerbation and IgE-mediated reaction is common in our country, especially in adult patients. In our case, latex-related urticaria was considered as flare-up CSU, resulting in antihistamine up-dosing that might have obscured the cutaneous symptoms of IgE-mediated latex allergy. The delayed recognition and missed diagnosis could have led to a severe reaction because her work exposed her to latex daily. The situation is similar to our previous study which exacerbated urticaria was frequently and falsely diagnosed in cases with adult-onset IgE-mediated food allergy. ${ }^{12}$ The pitfall that occurred needed to be addressed for the general practitioner. The proper management at the first anaphylaxis should be tryptase measurement ( 2 paired samples, peak and baseline tryptase), carrying self-injectable epinephrine, and allergist consultation to confirm culprit agent by demonstrating allergen-specific IgE. Although guidelines recommend referral to an allergist, this may not be feasible in many health care settings. ${ }^{13}$ Mushroom curry was erroneously concluded as causative to blame at the first episode, and long-term managed by $\mathrm{H} 1$-antihistamine up-dosing. Tryptase measurement and allergologic evaluation were not performed in 3 anaphylactic episodes before the allergist visit. The patient did not receive self-injectable epinephrine for her action plan. This could be due to various causes, including erroneous diagnosis, lack of awareness, management misconception, and lacking the experience to prepare and use the epinephrine-prefilled syringe. ${ }^{13,14}$

In conclusion, a concomitant of CSU might hinder the recognition of IgE-mediated reaction. Clinical history remains the most important part of allergologic evaluation. IgE-mediated allergy should be suspected in the following situations: 1) changing in CSU severity or frequency in previously controlled CSU patients, 2) the presence of systemic symptoms, compatible with anaphylaxis, 3) rash initially occurs at the exposure site of latex-containing medical gloves or devices in a related occupation, such as healthcare workers. In addition, a collaboration between emergency physicians and allergists with a goal toward agreement on criteria for diagnosis and indications for prescription of self-injectable epinephrine will improve the management of anaphylaxis.

\section{Ethics approval and consent to participate}

Written and informed consent was obtained from the patient to participate according to the Siriraj Institutional Review Board's requirements.

\section{Consent for publication}

Written and informed consent for publication was obtained from the patient. The patient was informed that de-identified data would be used in the scientific research and publications.

\section{Availability of data and materials Not applicable.}

\section{Authors' contributions}

All authors made a significant contribution to the work including the conceptualization, execution, acquisition of data, analysis, and interpretation. All authors participated in drafting, revising, or critically reviewing the manuscript, and gave final approval of the version to be published.

\section{Acknowledgment}

We thank Dr. Anthony Tan for editing the English language in the manuscript.

\section{Funding}

No funding has been received for this manuscript.

\section{Conflict of interest}

The authors declare that they have no competing interests.

\section{References}

1. Kelly KJ, Sussman G. Latex Allergy: Where Are We Now and How Did We Get There? J Allergy Clin Immunol Pract. 2017;5(5):1212-6.

2. Liberatore K, Kelly KJ. Latex Allergy Risks Live On. J Allergy Clin Immunol Pract. 2018;6(6):1877-8.

3. Wu M, McIntosh J, Liu J. Current prevalence rate of latex allergy: Why it remains a problem? J Occup Health. 2016;58(2):138-44.

4. Nucera E, Aruanno A, Rizzi A, Centrone M. Latex Allergy: Current Status and Future Perspectives. J Asthma Allergy. 2020;13:385-98.

5. Cabanes N, Igea JM, de la Hoz B, Agustin P, Blanco C, Dominguez J, et al. Latex allergy: Position Paper. J Investig Allergol Clin Immunol. 2012;22(5):313-30; quiz follow 30

6. Parisi CA, Petriz NA, Busaniche JN, Cortines MC, Frangi FA, Portillo SA, et al. Prevalence of latex allergy in a population of patients diagnosed with myelomeningocele. Arch Argent Pediatr. 2016;114(1):30-5.

7. Katrancha ED, Harshberger LA. Nursing students with latex allergy. Nurse Educ Pract. 2012;12(6):328-32.

8. Poley GE, Jr., Slater JE. Latex allergy. J Allergy Clin Immunol. 2000;105(6 Pt 1):1054-62

9. Sompornrattanaphan M, Kreetapirom P, Srinoulprasert Y, Kanistanon D, Klinniyom A, Wongsa C, et al. Severe anaphylaxis after pelvic examination: a case report of dual latex and chlorhexidine allergies. Allergy Asthma Clin Immunol. 2019;15:19.

10. Fricke J, Avila G, Keller T, Weller K, Lau S, Maurer M, et al. Prevalence of chronic urticaria in children and adults across the globe: Systematic review with meta-analysis. Allergy. 2020;75(2):423-32.

11. Xu YY, Jiang NN, Wen LP, Li H, Yin J. Wheat allergy in patients with recurrent urticaria. World Allergy Organ J. 2019;12(2):100013.

12. Thongngarm $\mathrm{T}$, Wongsa $\mathrm{C}$, Pacharn $\mathrm{P}$, Piboonpocanun $\mathrm{S}$, Sompornrattanaphan M. Clinical Characteristics and Proposed Wheat -Cofactor Challenge Protocol with a High Diagnostic Yield in Adult -Onset IgE-Mediated Wheat Allergy. J Asthma Allergy. 2020;13:355-68.

13. Campbell RL, Luke A, Weaver AL, St Sauver JL, Bergstralh EJ, Li JT, et al. Prescriptions for self-injectable epinephrine and follow-up referral in emergency department patients presenting with anaphylaxis. Ann Allergy Asthma Immunol. 2008;101(6):631-6.

14. Waserman S, Avilla E, Ben-Shoshan M, Rosenfield L, Adcock AB, Greenhawt M. Epinephrine Autoinjectors: New Data, New Problems. J Allergy Clin Immunol Pract. 2017;5(5):1180-91. 